\title{
Urinary Angiotensinogen as a Biomarker of Nephropathy in Childhood
}

\author{
Maki Urushihara and Shoji Kagami \\ Department of Pediatrics, Institute of Health Biosciences, The University of Tokushima Graduate School, Kuramoto-cho 3-18-15, \\ Tokushima 770-8503, Japan \\ Correspondence should be addressed to Maki Urushihara, urushihara@clin.med.tokushima-u.ac.jp
}

Received 14 March 2011; Revised 21 June 2011; Accepted 21 June 2011

Academic Editor: Michel Fischbach

Copyright ( $) 2011$ M. Urushihara and S. Kagami. This is an open access article distributed under the Creative Commons Attribution License, which permits unrestricted use, distribution, and reproduction in any medium, provided the original work is properly cited.

\begin{abstract}
While most circulating angiotensinogen (AGT) is synthesized in the liver, the kidneys also produce AGT. Recently, we reported that urinary AGT is mainly originated from AGT. Using newly developed human AGT ELISA, we measured urinary AGT levels in chronic glomerulonephritis (GN) patients and patients with type 1 diabetes in childhood. Urinary AGT level was positively correlated with diastolic blood pressure, urinary albumin, urinary protein levels, and urinary occult blood in chronic GN patients. Furthermore, urinary AGT level was significantly increased in chronic GN patients not treated with renin-angiotensin system (RAS) blockers compared with control subjects. Importantly, patients treated with RAS blockers had a marked attenuation of this increase. Also, urinary AGT level was significantly higher in patients with diabetic nephropathy in the premicroalbuminuric phase than in control subjects. These results suggest that urinary AGT reflects intrarenal RAS status in chronic GN and may be an early marker of diabetic nephropathy.
\end{abstract}

\section{Introduction}

The renin-angiotensin system (RAS) plays a critical role in arterial pressure and sodium homeostasis [1]. Angiotensin II (Ang II) is the most powerful biologically active product of the RAS [2]. Recently, the focus of interest in the RAS has shifted toward the role of the local/tissue RAS in specific tissues [2]. Angiotensinogen (AGT) is the only known substrate for renin that is a rate-limiting enzyme of the RAS. Because the level of AGT is close to the Michaelis-Menten constant for renin, not only renin levels but also AGT levels can control RAS activity, and AGT upregulation may lead to elevated angiotensin peptide levels and increased blood pressure [3]. Recent studies of experimental animal models and transgenic mice have documented AGT involvement in the activation of the RAS and development of hypertension $[4,5]$. Genetic manipulations that lead to AGT overexpression have consistently been shown to cause hypertension [6, 7]. In human genetic studies, a linkage has been established between the AGT gene and hypertension [8]. Enhanced intrarenal AGT mRNA and/or protein levels have also been observed in multiple experimental models of hypertension including Ang II-dependent hypertensive rats [9-12], Dahl salt-sensitive hypertensive rats $[13,14]$, and spontaneously hypertensive rats [15], as well as in kidney diseases including diabetic nephropathy [16-20], IgA nephropathy [21, 22], and radiation nephropathy [23]. Thus, AGT plays an important role in the development and progression of hypertension and kidney disease $[2,24]$. Recent studies showed that urinary excretion rates of AGT provided a specific index of intrarenal RAS status [2, 25, 26]. This paper explores recent findings concerning the use of urinary AGT as a potential biomarker of intrarenal RAS status in childhood nephropathy.

\section{Intrarenal RAS}

The role of RAS in blood pressure regulation and sodium and fluid homeostasis is well recognized [2]. The biologically active peptides that are formed from AGT include Ang II and Ang 1-7. The balance between the vasoconstricting actions of Ang II, mediated by the $\mathrm{AT}_{1}$ receptor, is countered by the 


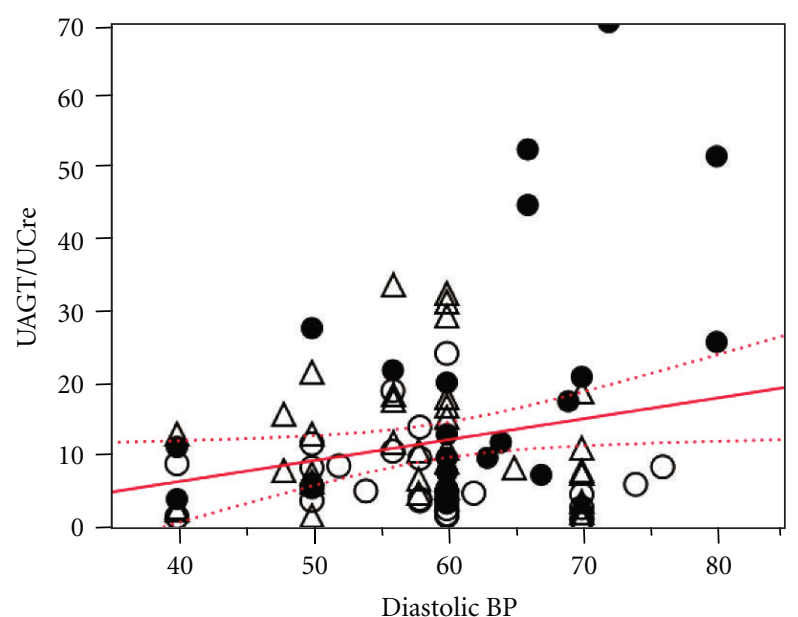

$\mathrm{UAGT} / \mathrm{UCre}=-5.34+0.29$ diastolic $\mathrm{BP}$ $r=0.2218, P=0.0326$

(a)

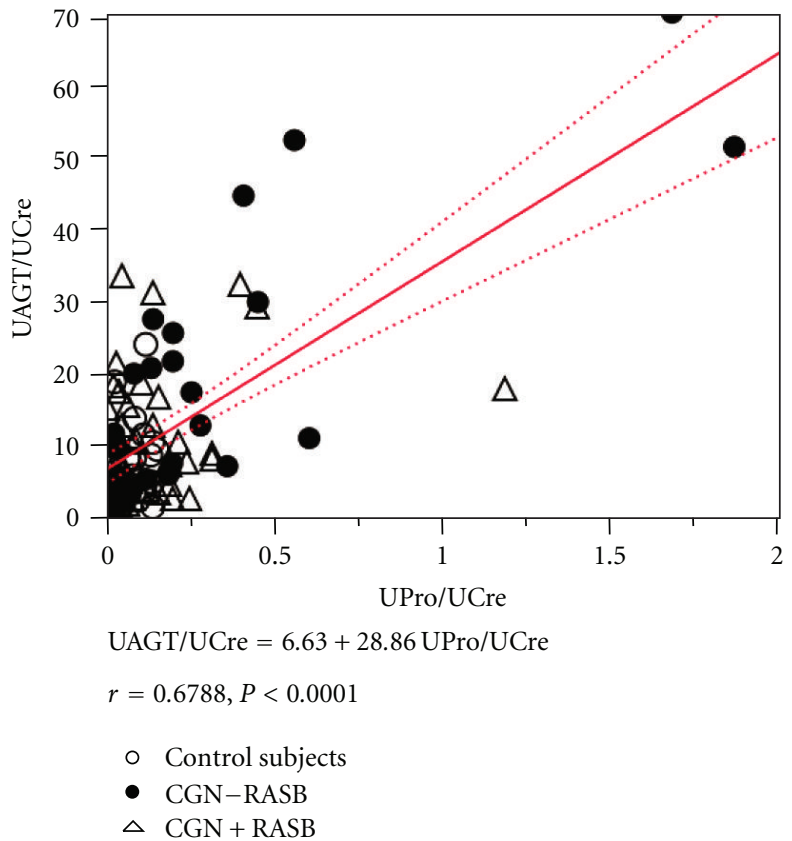

(c)

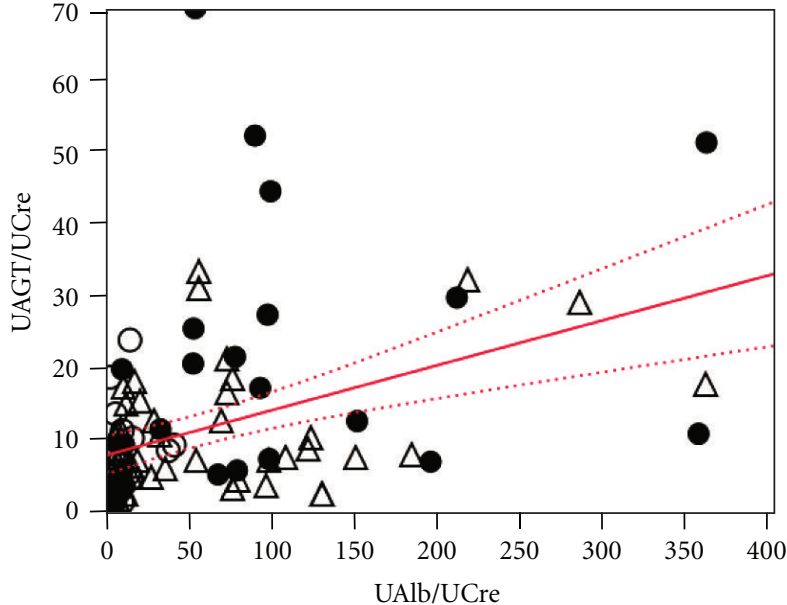

$\mathrm{UAGT} / \mathrm{UCre}=8.01+0.06 \mathrm{UAlb} / \mathrm{UCre}$ $r=0.4089, P<0.0001$

(b)

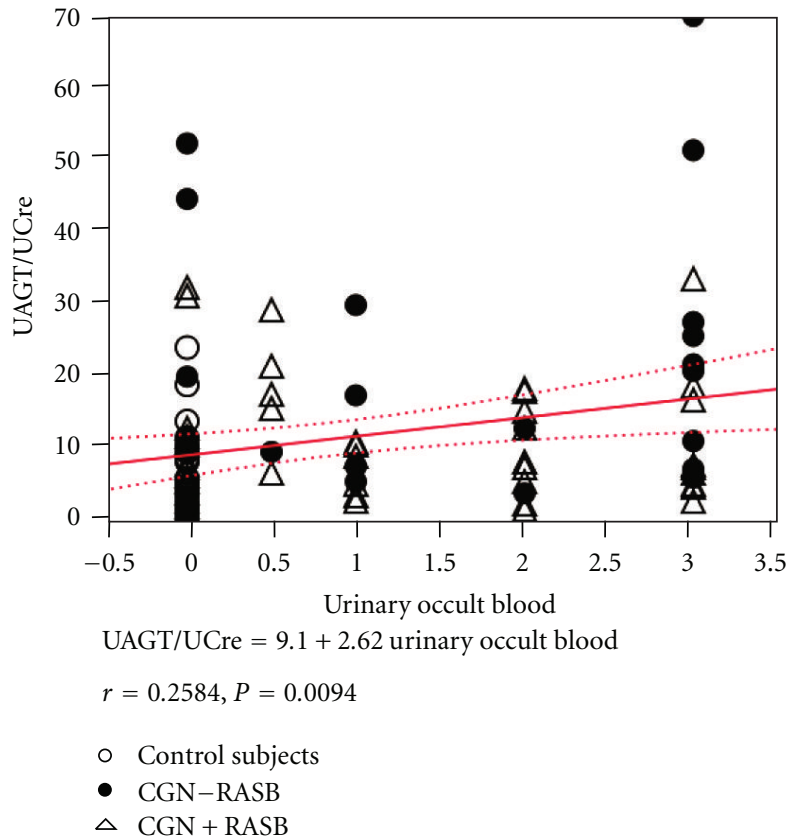

(d)

FIGURE 1: Single regression analyses for urinary AGT-creatinine ratio with diastolic blood pressure (a), urinary albumin-creatinine ratio (b), urinary protein-creatinine ratio (c), and urinary occult blood index (d), respectively, in chronic glomerulonephritis (CGN) patients with/without renin-angiotensin system blockade (RASB) and in control subjects. Cited from Am J Nephrol 2010; 31:318-325 by Urushihara et al. [47].

vasodilating actions of Ang II, mediated by the $\mathrm{AT}_{2}$ receptor [27], and Ang 1-7 acting on the G protein-coupled receptor Mas [28]. Formation of Ang II is dependent upon the substrate availability of AGT and Ang I and the activities of renin, ACE, ACE2, and ACE-independent enzymatic pathways including serine proteases, tonin, cathepsin G, trypsin, and kallikrein. The actions of Ang II are determined by signaling via AT1 and AT2 receptors and the putative Ang 1-7 receptor Mas [29].
Local/tissue RAS in specific tissues has become the focus of much recent interest [30]. Emerging evidence has demonstrated the importance of tissue-specific RAS in the brain [31], heart [32], adrenal glands [33], and vasculature $[34,35]$ as well as the kidneys [24]. In particular, renal RAS is unique because all of the components necessary to generate intrarenal Ang II are present along the nephron in both interstitial and intratubular compartments $[2,29]$. The presence of AGT gene transcription in the proximal tubules 


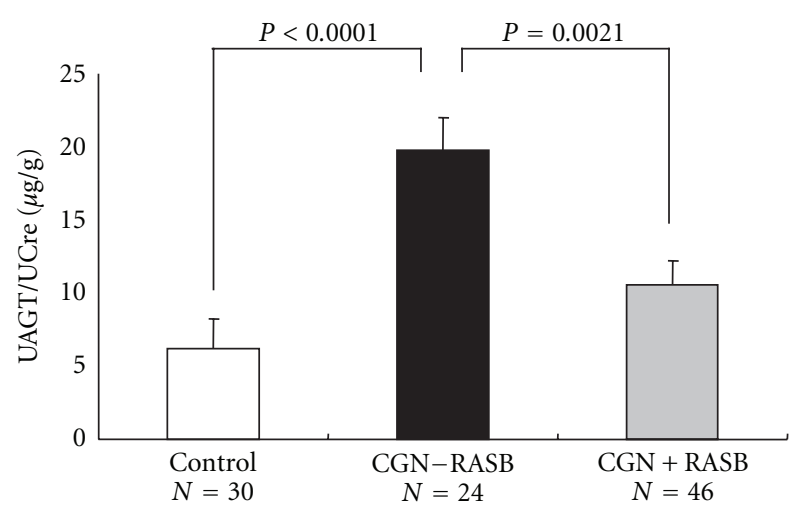

FIgure 2: Urinary AGT-creatinine ratio in chronic glomerulonephritis patients (CGN) with/without renin-angiotensin system blockade (RASB) and in control subjects. Cited from Am J Nephrol 2010; 31: 318-325 by Urushihara et al. [47].

has been shown using in situ hybridization [36]. AGT mRNA is expressed primarily in the proximal convoluted tubules and proximal straight tubules, with small amounts in glomeruli, vasa recta, and renal vasculature [37]. Renal AGT protein is abundant in the proximal convoluted tubules [38]. Strong positive immunostaining for AGT protein has been reported in proximal convoluted tubules and proximal straight tubules, and weak positive staining in glomeruli and vasa recta; however, distal tubules and collecting ducts are negative [9]. The AGT synthesized in the kidney is secreted into the lumen leading to Ang I generation. Low but measurable renin concentrations have been detected in proximal tubule fluid in rats [2].

Renin mRNA and renin-like activity have been demonstrated in cultured proximal tubular cells [39]. The brush border membrane of proximal human kidney tubules expresses abundant levels of ACE mRNA [40] and protein [41]. ACE has also been measured in proximal and distal tubular fluid but is greater in proximal tubule fluid [42]. Therefore, all the major components required to generate Ang II are expressed within the kidneys $[2,24]$.

\section{Urinary AGT as a New Biomarker of Intrarenal RAS Status}

Recently, urinary AGT excretion rates were reported to provide a specific index of intrarenal RAS status in Ang IIdependent hypertensive rats $[9,11,12]$. Moreover, urinary AGT levels were reported to reflect intrarenal Ang II activity associated with increased risk of renal function deterioration in chronic kidney disease patients [25]. A direct quantitative method to measure urinary AGT using human AGT enzymelinked immunosorbent assays (ELISA) was developed [43], which indicated significantly increased urinary AGT levels in hypertensive patients not treated with RAS blockers compared with normotensive subjects. Importantly, patients treated with RAS blockers exhibited a marked attenuation of this AGT increase [26]. These data prompted us to measure urinary AGT in chronic GN patients and patients with type 1 diabetes in childhood.

\section{Urinary AGT Reflects Intrarenal RAS Status in Chronic Glomerulonephritis}

Chronic glomerulonephritis (GN) resulting in substantial renal damage is frequently characterized by relentless progression to end-stage renal disease. Renal Ang II, production of which is enhanced in chronic GN, can elevate the intraglomerular pressure, increase glomerular cell hypertrophy, and augment extracellular matrix accumulation [44]. ACEi and/or ARB are often administered to patients with proteinuric nephropathies $[45,46]$. This may reflect the relatively short-term nature and small sample size of these studies but may also be an indication that factors other than Ang II play an important role in progression of renal disease.

Previously, we examined glomerular AGT expression and its correlation with expression of other RAS components and levels of glomerular injury in samples from patients with IgA nephropathy and minor glomerular abnormalities [22]. Immunohistochemistry showed that AGT was highly expressed in nephritic glomeruli affected by IgA nephropathy compared with glomeruli affected by minor glomerular abnormalities. Levels of glomerular AGT protein were well correlated with levels of glomerular Ang II, transforming growth factor- $\beta$ (TGF- $\beta$ ), $\alpha$-smooth-muscle actin, glomerular cell number, and glomerulosclerosis score. These data suggest that activated glomerular AGT expression is likely involved in elevated local Ang II production and, thereby, may contribute to increased TGF- $\beta$ production and development of glomerular injury in IgA nephropathy.

Based on these findings, a newly developed human AGT ELISA was used to elucidate urinary AGT levels in chronic GN patients [43]. To demonstrate that urinary AGT reflects intrarenal RAS status in chronic GN patients during childhood, 100 urine samples from 70 patients with chronic GN and 30 normal control subjects were recruited [47]. All patients had normal kidney function, and their background renal diseases were IgA nephropathy $(n=26)$, purpura nephritis $(n=24)$, lupus nephritis $(n=8)$, focal segmental glomerulosclerosis $(n=7)$, and non-IgA mesangial proliferative GN $(n=5)$. Urinary AGT-creatinine ratios did not correlate with sex, age, height, body weight, body mass index, systolic blood pressure, serum sodium levels, serum potassium levels, serum creatinine levels, estimated glomerular filtration rate (eGFR), urinary fractional excretion of sodium, or plasma AGT levels. However, urinary AGTcreatinine ratios significantly positively correlated with diastolic blood pressure (Figure 1(a); $r=0.2218, P=0.0326$ ), urinary albumin-creatinine ratios (Figure $1(\mathrm{~b}) ; r=0.4089$, $P<0.0001$ ), urinary protein-creatinine ratios (Figure 1(c); $r=0.6788, P<0.0001)$, and urinary occult blood (Figure 1(d); $r=0.2584, P=0.0094$ ).

Increased intrarenal AGT immunoreactivity was previously reported in IgA nephropathy patients and found to be significantly positively correlated with urinary protein-creatinine ratio [21]. Increases in protein-creatinine ratio generally reflect the severity of renal disease [48]. Therefore, taken together, these data suggest that urinary AGT levels may be a marker of the severity of chronic GN. This perspective is supported by recent clinical studies $[25,49]$. As shown 


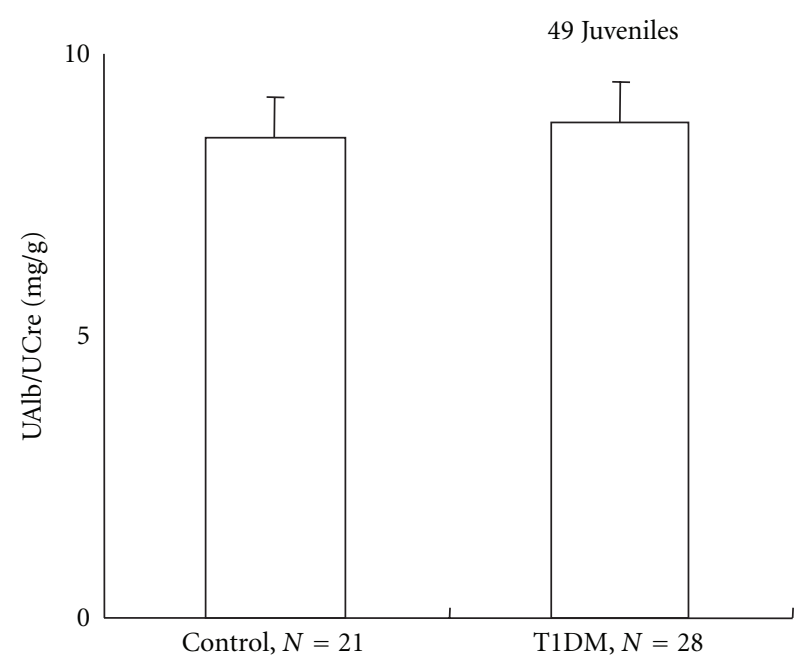

(a)

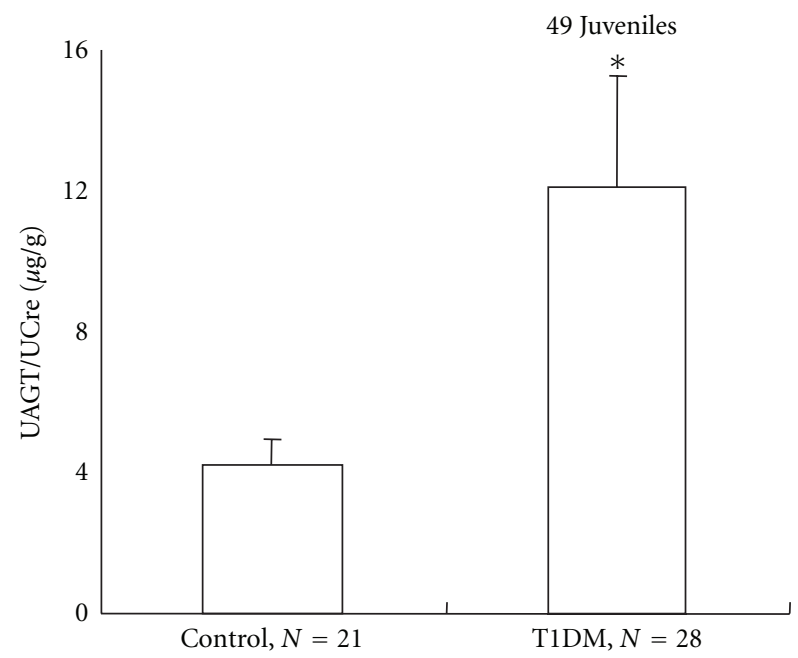

(c)

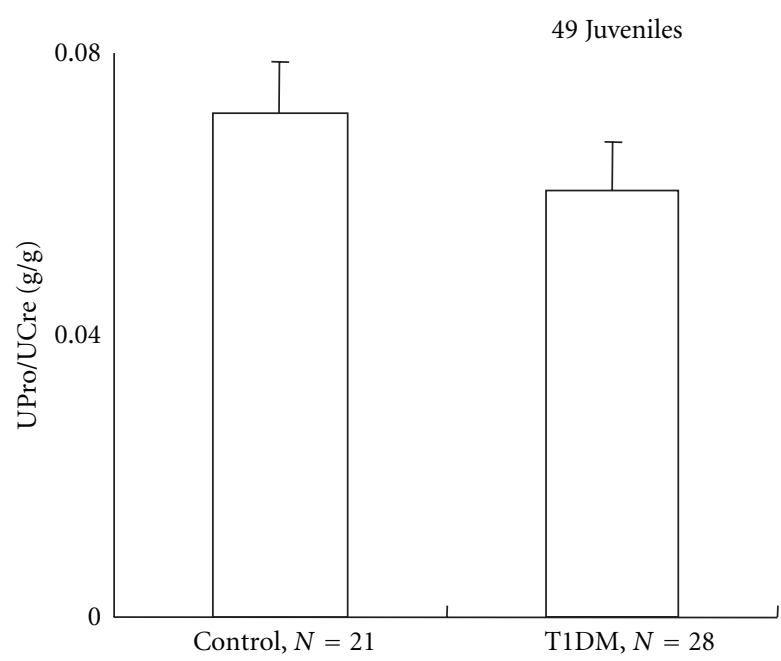

(b)

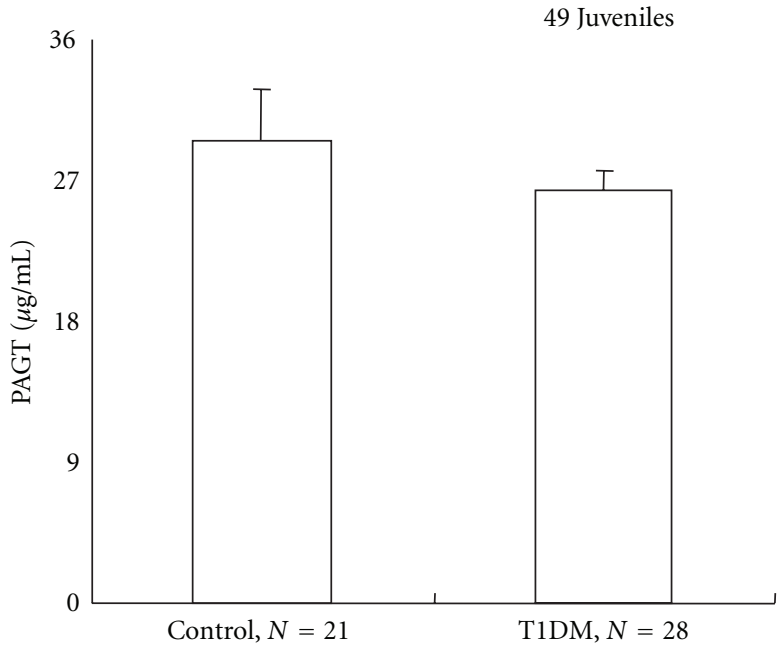

(d)

FIGURE 3: Urinary albumin-creatinine ratio (a) and urinary protein-creatinine ratio (b) were not increased in patients with type 1 diabetes (T1DM) compared to control subjects, suggesting that these patients were in the pre-microalbuminuric phase of diabetic nephropathy. However, urinary AGT-creatinine ratio was significantly increased in these patients compared to control subjects (c). Importantly, the AGT increase was not observed in plasma (d). Cited from Am J Med Sci 2009; 338: 478-480 by Saito et al. [56].

in Figure 2, urinary AGT-creatinine ratios were significantly increased in chronic GN patients not treated with RAS blockers $(19.79 \pm 3.70 \mu \mathrm{g} / \mathrm{g})$ compared with control subjects $(6.22 \pm 0.98, P<0.0001)$ [47]. Importantly, the use of RAS blockers attenuated this increase $(10.58 \pm 1.23, P=0.0021)$. These data suggest that urinary AGT can be used to assess the efficacy of RAS blockade in reducing intrarenal RAS activity.

Although most circulating AGT is produced and secreted by the liver, the kidneys also produce AGT [2]. Intrarenal AGT mRNA and protein have been localized to proximal tubule cells, indicating that intratubular Ang II could be derived from locally produced and secreted AGT $[36,38]$. The AGT produced in proximal tubule cells appears to be secreted directly into the tubular lumen, in addition to producing its metabolites intracellularly and secreting these into the tubular lumen [50]. Proximal tubular AGT concen- trations in anesthetized rats have been reported in the range of 300-600 nM, which greatly exceeds the free Ang I and Ang II concentrations in tubular fluid [24]. Plasma AGT seems unlikely to filter across the glomerular membrane at high levels due to its molecular size $(50-60 \mathrm{kDa})$, further supporting the concept that proximal tubular cells secrete AGT directly into the tubules [51].

To determine if circulating AGT is a source of urinary AGT, human AGT was infused into hypertensive and normotensive rats [14]. However, human AGT was detectable in plasma but not detectable in the urine of rats, indicating limited glomerular permeability and/or tubular degradation. These findings support the hypothesis that urinary AGT is derived from the AGT produced and secreted by the proximal tubules and not from plasma. In agreement with this concept, plasma AGT levels were not correlated 
with urinary AGT-creatinine ratios in this study. Moreover, plasma AGT levels were unchanged across the three groups even though urinary AGT-creatinine ratios demonstrated significant differences. Therefore, AGT in urine seems highly likely to originate from AGT in the kidney, not from AGT in plasma. These data suggest that urinary AGT is a potential novel biomarker of the intrarenal RAS status in chronic GN. The efficacy of RAS blockade to reduce the intrarenal RAS activity can, thus, be confirmed by measurements of urinary AGT excretion rates.

\section{Urinary AGT as a New Biomarker of Intrarenal RAS Status in Type 1 Diabetes}

Microalbuminuria is the most commonly used early marker of diabetic nephropathy [52], and diabetic nephropathy is thought to be a unidirectional process from microalbuminuria to end-stage renal failure [53]. However, recent studies in type 1 diabetic patients demonstrate that a large proportion of diabetic nephropathy patients revert to normoalbuminuria and that one-third of these patients exhibit reduced renal function even in the microalbuminuria stage [54]. Urinary inflammatory markers are thought to be high in microalbuminuric type 1 diabetic patients with diminished renal function but not in those with stable renal function. However, no single marker has been sufficient to represent the whole panel [55]. Therefore, a more sensitive and more specific marker for diabetic nephropathy would be highly advantageous.

To demonstrate whether urinary AGT levels can be dissociated from urinary albumin or protein exertion rates in type 1 diabetic juveniles, early-phase studies were performed in type 1 diabetic juveniles $(n=34)$ and sex- and age-matched control subjects $(n=21)$ [56]. Since the primary focus of the study was comparing the characteristics of normoalbuminuric patients with type 1 diabetes with those of control subjects, 6 microalbuminuric patients with type 1 diabetes (urinary albumin-creatinine ratio $>30 \mathrm{mg} / \mathrm{g}$ ) were excluded. Consequently, urine and plasma samples from 28 diabetic patients were analyzed ( $n=49$ total juveniles). No patients received treatment with RAS blockers. Neither urinary albumin-creatinine ratios nor urinary protein-creatinine ratios were significantly increased in these type 1 diabetic patients compared to control subjects (urinary albumin-creatinine ratio: $8.8 \pm 0.7 \mathrm{mg} / \mathrm{g}$ versus $8.5 \pm 1.1 \mathrm{mg} / \mathrm{g}, P=0.8450$; urinary protein-creatinine ratio: $0.060 \pm 0.010 \mathrm{~g} / \mathrm{g}$ versus $0.070 \pm 0.010 \mathrm{~g} / \mathrm{g}, P=0.3231$ ), suggesting that these patients were in the premicroalbuminuric phase of diabetic nephropathy (Figures 3(a) and 3(b)). However, urinary AGT-creatinine ratios were significantly increased in these patients compared to control subjects $(12.1 \pm 3.2 \mu \mathrm{g} / \mathrm{g}$ versus $4.2 \pm 0.7 \mu \mathrm{g} / \mathrm{g}, P=0.0454$ ) (Figure 3(c)). Importantly, AGT was not increased in plasma $(26.3 \pm 1.3 \mu \mathrm{g} / \mathrm{ml}$ versus $29.5 \pm 3.3 \mu \mathrm{g} / \mathrm{ml}, P=0.3148$ ) (Figure 3(d)). These data indicate that urinary AGT levels are increased in type 1 diabetic subjects and that increased urinary AGT levels precede increased urinary albumin levels. Thus, urinary AGT levels may serve as a very sensitive early marker of intrarenal
RAS activation and may be one of the earliest predictors of diabetic nephropathy in diabetic patients [56].

\section{Conclusion and Future Prospects}

Recent findings indicate that urinary AGT is increased in chronic GN patients, and treatment with RAS blockers suppresses urinary AGT. The efficacy of RAS blockade in reducing intrarenal RAS activity can be confirmed by measurement of urinary AGT in chronic GN patients. Although the relatively small sample size is a potential limitation, this study demonstrated a statistically significant relationship between urinary AGT and diastolic blood pressure, urinary albu$\mathrm{min} /$ protein levels, and occult blood in patients with chronic GN. We recognized that a larger multicenter, randomized control study is required to extend the clinical applicability of these observations. A prospective study to determine the relationship between the effect of RAS blockade on urinary AGT and urinary albumin/protein would be helpful in assessing the clinical significance of the decrease in urinary AGT associated with RAS blockade. These research projects will establish a novel diagnostic test to identify those chronic GN patients most likely to respond to a RAS blockade, which could provide useful information to allow a mechanistic rationale for a more educated selection of an optimized approach to treatment of chronic GN patients. Increased urinary AGT levels are also observed in patients with type 1 diabetes, and this increase precedes an increase in urinary albumin levels, suggesting that urinary AGT may function as an early marker of diabetic nephropathy. Randomized clinical trials have been projected to establish novel diagnostic tests to identify those patients most likely to respond to RAS blockade. These trials could provide information useful to developing a mechanistic rationale for improved selection of optimized treatments in patients with chronic GN or type 1 diabetes in childhood.

\section{References}

[1] L. G. Navar, L. M. Harrison-Bernard, J. D. Imig, C. T. Wang, L. Cervenka, and K. D. Mitchell, "Intrarenal angiotensin II generation and renal effects of AT1 receptor blockade," Journal of the American Society of Nephrology, vol. 10, no. 4, pp. S266S272, 1999.

[2] H. Kobori, M. Nangaku, L. G. Navar, and A. Nishiyama, "The intrarenal renin-angiotensin system: from physiology to the pathobiology of hypertension and kidney disease," Pharmacological Reviews, vol. 59, no. 3, pp. 251-287, 2007.

[3] A. R. Brasier and J. Li, "Mechanisms for inducible control of angiotensinogen gene transcription," Hypertension, vol. 27, no. 3, pp. 465-475, 1996.

[4] S. Sachetelli, Q. Liu, S. L. Zhang et al., "RAS blockade decreases blood pressure and proteinuria in transgenic mice overexpressing rat angiotensinogen gene in the kidney," Kidney International, vol. 69, no. 6, pp. 1016-1023, 2006.

[5] H. Kobori, Y. Ozawa, R. Satou et al., "Kidney-specific enhancement of ANG II stimulates endogenous intrarenal angiotensinogen in gene-targeted mice," American Journal of Physiology, vol. 293, no. 3, pp. F938-F945, 2007.

[6] O. Smithies and H. S. Kim, "Targeted gene duplication and disruption for analyzing quantitative genetic traits in mice," 
Proceedings of the National Academy of Sciences of the United States of America, vol. 91, no. 9, pp. 3612-3615, 1994.

[7] H. S. Kim, J. H. Krege, K. D. Kluckman et al., "Genetic control of blood pressure and the angiotensinogen locus," Proceedings of the National Academy of Sciences of the United States of America, vol. 92, no. 7, pp. 2735-2739, 1995.

[8] Y. Y. Zhao, J. Zhou, C. S. Narayanan, Y. Cui, and A. Kumar, "Role of C/A polymorphism at -20 on the expression of human angiotensinogen gene," Hypertension, vol. 33, no. 1, pp. 108-115, 1999.

[9] H. Kobori, L. M. Harrison-Bernard, and L. G. Navar, "Expression of angiotensinogen mRNA and protein in angiotensin IIdependent hypertension," Journal of the American Society of Nephrology, vol. 12, no. 3, pp. 431-439, 2001.

[10] H. Kobori, L. M. Harrison-Bernard, and L. G. Navar, "Enhancement of angiotensinogen expression in angiotensin II-dependent hypertension," Hypertension, vol. 37, no. 5, pp. 1329-1335, 2001.

[11] H. Kobori, A. Nishiyama, L. M. Harrison-Bernard, and L. Gabriel Navar, "Urinary angiotensinogen as an indicator of intrarenal angiotensin status in hypertension," Hypertension, vol. 41, no. 1, pp. 42-49, 2003.

[12] H. Kobori, M. C. Prieto-Carrasquero, Y. Ozawa, and L. G. Navar, "AT1 receptor mediated augmentation of intrarenal angiotensinogen in angiotensin II-dependent hypertension," Hypertension, vol. 43, no. 5, pp. 1126-1132, 2004.

[13] H. Kobori and A. Nishiyama, "Effects of tempol on renal angiotensinogen production in Dahl salt-sensitive rats," Biochemical and Biophysical Research Communications, vol. 315, no. 3, pp. 746-750, 2004.

[14] H. Kobori, A. Nishiyama, Y. Abe, and L. G. Navar, "Enhancement of intrarenal angiotensinogen in Dahl salt-sensitive rats on high salt diet," Hypertension, vol. 41, no. 3 I, pp. 592-597, 2003.

[15] H. Kobori, Y. Ozawa, Y. Suzaki, and A. Nishiyama, "Enhanced intrarenal angiotensinogen contributes to early renal injury in spontaneously hypertensive rats," Journal of the American Society of Nephrology, vol. 16, no. 7, pp. 2073-2080, 2005.

[16] Y. Nagai, L. Yao, H. Kobori et al., "Temporary angiotensin II blockade at the prediabetic stage attenuates the development of renal injury in type 2 diabetic rats," Journal of the American Society of Nephrology, vol. 16, no. 3, pp. 703-711, 2005.

[17] R. Singh, A. K. Singh, and D. J. Leehey, "A novel mechanism for angiotensin II formation in streptozotocin-diabetic rat glomeruli," American Journal of Physiology, vol. 288, no. 6, pp. F1183-F1190, 2005.

[18] Y. Suzaki, Y. Ozawa, and H. Kobori, "Intrarenal oxidative stress and augmented angiotensinogen are precedent to renal injury in Zucker diabetic fatty rats," International Journal of Biological Sciences, vol. 3, no. 1, pp. 40-46, 2007.

[19] K. Miyata, N. Ohashi, Y. Suzaki, A. Katsurada, and H. Kobori, "Sequential activation of the reactive oxygen species/ angiotensinogen/renin-angiotensin system axis in renal injury of type 2 diabetic rats," Clinical and Experimental Pharmacology and Physiology, vol. 35, no. 8, pp. 922-927, 2008.

[20] D. J. Leehey, A. K. Singh, J. P. Bast, P. Sethupathi, and R. Singh, "Glomerular renin angiotensin system in streptozotocin diabetic and Zucker diabetic fatty rats," Translational Research, vol. 151, no. 4, pp. 208-216, 2008.

[21] H. Kobori, A. Katsurada, Y. Ozawa et al., "Enhanced intrarenal oxidative stress and angiotensinogen in IgA nephropathy patients," Biochemical and Biophysical Research Communications, vol. 358, no. 1, pp. 156-163, 2007.
[22] M. Takamatsu, M. Urushihara, S. Kondo et al., "Glomerular angiotensinogen protein is enhanced in pediatric IgA nephropathy," Pediatric Nephrology, vol. 23, no. 8, pp. 1257-1267, 2008.

[23] H. Kobori, Y. Ozawa, Y. Suzaki et al., "Young Scholars Award Lecture: intratubular angiotensinogen in hypertension and kidney diseases," American Journal of Hypertension, vol. 19, no. 5, pp. 541-550, 2006.

[24] L. G. Navar, L. M. Harrison-Bernard, A. Nishiyama, and H. Kobori, "Regulation of intrarenal angiotensin II in hypertension," Hypertension, vol. 39, no. 2, pp. 316-322, 2002.

[25] T. Yamamoto, T. Nakagawa, H. Suzuki et al., "Urinary angiotensinogen as a marker of intrarenal angiotensin II activity associated with deterioration of renal function in patients with chronic kidney disease," Journal of the American Society of Nephrology, vol. 18, no. 5, pp. 1558-1565, 2007.

[26] H. Kobori, A. B. Alper, R. Shenava et al., "Urinary angiotensinogen as a novel biomarker of the intrarenal reninangiotensin system status in hypertensive patients," Hypertension, vol. 53, no. 2, pp. 344-350, 2009.

[27] R. M. Carey and H. M. Siragy, "The intrarenal reninangiotensin system and diabetic nephropathy," Trends in Endocrinology and Metabolism, vol. 14, no. 6, pp. 274-281, 2003.

[28] R. A. S. Santos, A. C. Simoes e Silva, C. Maric et al., "Angiotensin-(1-7) is an endogenous ligand for the G proteincoupled receptor Mas," Proceedings of the National Academy of Sciences of the United States of America, vol. 100, no. 14, pp. 8258-8263, 2003.

[29] L. G. Navar, M. C. Prieto-Carrasquero, and H. Kobori, Molecular Aspects of the Renal Renin-Angiotensin System, chapter 1, Taylor \& Francis Medical, Oxfordshine, UK, 1st edition, 2006.

[30] V. J. Dzau and R. Re, "Tissue angiotensin system in cardiovascular medicine: a paradigm shift?” Circulation, vol. 89, no. 1, pp. 493-498, 1994.

[31] O. Baltatu, J. A. Silva, D. Ganten, and M. Bader, "The brain renin-angiotensin system modulates angiotensin II-induced hypertension and cardiac hypertrophy," Hypertension, vol. 35, no. 1, pp. 409-412, 2000.

[32] L. J. Dell'Italia, Q. C. Meng, E. Balcells et al., "Compartmentalization of angiotensin II generation in the dog heart: evidence for independent mechanisms in intravascular and interstitial spaces," Journal of Clinical Investigation, vol. 100, no. 2, pp. 253-258, 1997.

[33] G. Mazzocchi, L. K. Malendowicz, A. Markowska, G. Albertin, and G. G. Nussdorfer, "Role of adrenal renin-angiotensin system in the control of aldosterone secretion in sodiumrestricted rats," American Journal of Physiology, vol. 278, no. 6, pp. E1027-E1030, 2000.

[34] K. K. Griendling, C. A. Minieri, J. D. Ollerenshaw, and R. W. Alexander, "Angiotensin II stimulates NADH and NADPH oxidase activity in cultured vascular smooth muscle cells," Circulation Research, vol. 74, no. 6, pp. 1141-1148, 1994.

[35] A. H. J. Danser, P. J. J. Admiraal, F. H. M. Derkx, and M. A. D. H. Schalekamp, "Angiotensin I-to-II conversion in the human renal vascular bed," Journal of Hypertension, vol. 16, no. 12, part 2, pp. 2051-2056, 1998.

[36] J. R. Ingelfinger, W. M. Zuo, E. A. Fon, K. E. Ellison, and V. J. Dzau, "In situ hybridization evidence for angiotensinogen messenger RNA in the rat proximal tubule. An hypothesis for the intrarenal renin angiotensin system," Journal of Clinical Investigation, vol. 85, no. 2, pp. 417-423, 1990.

[37] Y. Terada, K. Tomita, H. Nonoguchi, and F. Marumo, "PCR localization of angiotensin II receptor and angiotensinogen 
mRNAs in rat kidney," Kidney International, vol. 43, no. 6, pp. 1251-1259, 1993.

[38] I. A. Darby and C. Sernia, "In situ hybridization and immunohistochemistry of renal angiotensinogen in neonatal and adult rat kidneys," Cell and Tissue Research, vol. 281, no. 2, pp. 197-206, 1995.

[39] W. L. Henrich, E. A. McAllister, A. Eskue, T. Miller, and O. W. Moe, "Renin regulation in cultured proximal tubular cells," Hypertension, vol. 27, no. 6, pp. 1337-1340, 1996.

[40] M. Sibony, J. M. Gasc, F. Soubrier, F. Alhenc-Gelas, and P. Corvol, "Gene expression and tissue localization of the two isoforms of angiotensin I converting enzyme," Hypertension, vol. 21, no. 6, part 1, pp. 827-835, 1993.

[41] C. P. Vío and V. A. Jeanneret, "Local induction of angiotensinconverting enzyme in the kidney as a mechanism of progressive renal diseases," Kidney International, Supplement, vol. 64, no. 86, pp. S57-S63, 2003.

[42] D. E. Casarini, M. A. Boim, R. C. R. Stella, M. H. KriegerAzzolini, J. E. Krieger, and N. Schor, "Angiotensin I-converting enzyme activity in tubular fluid along the rat nephron," American Journal of Physiology, vol. 272, no. 3, pp. F405-F409, 1997.

[43] A. Katsurada, Y. Hagiwara, K. Miyashita et al., "Novel sandwich ELISA for human angiotensinogen," American Journal of Physiology, vol. 293, no. 3, pp. F956-F960, 2007.

[44] D. E. Kohan, "Angiotensin II and endothelin in chronic glomerulonephritis," Kidney International, vol. 54, no. 2, pp. 646-647, 1998.

[45] Y. Horita, M. Tadokoro, K. Taura et al., "Low-dose combination therapy with temocapril and losartan reduces proteinuria in normotensive patients with immunoglobulin A nephropathy," Hypertension Research, vol. 27, no. 12, pp. 963-970, 2004.

[46] P. Ruggenenti, A. Perna, G. Gherardi, F. Gaspari, R. Benini, and G. Remuzzi, "Renal function and requirement for dialysis in chronic nephropathy patients on long-term ramipril: REIN follow-up trial," The Lancet, vol. 352, no. 9136, pp. 1252-1256, 1998.

[47] M. Urushihara, S. Kondo, S. Kagami, and H. Kobori, "Urinary angiotensinogen accurately reflects intrarenal reninangiotensin system activity," American Journal of Nephrology, vol. 31, no. 4, pp. 318-325, 2010.

[48] B. R. Hemmelgarn, B. J. Manns, A. Lloyd et al., "Relation between kidney function, proteinuria, and adverse outcomes," Journal of the American Medical Association, vol. 303, no. 5, pp. 423-429, 2010.

[49] H. Kobori, N. Ohashi, A. Katsurada et al., "Urinary angiotensinogen as a potential biomarker of severity of chronic kidney diseases," Journal of the American Society of Hypertension, vol. 2, no. 5, pp. 349-354, 2008.

[50] P. Lantelme, A. Rohrwasser, B. Gociman et al., "Effects of dietary sodium and genetic background on angiotensinogen and Renin in mouse," Hypertension, vol. 39, no. 5, pp. 10071014, 2002.

[51] A. Rohrwasser, T. Morgan, H. F. Dillon et al., "Elements of a paracrine tubular renin-angiotensin system along the entire nephron," Hypertension, vol. 34, no. 6, pp. 1265-1274, 1999.

[52] J. Coresh, E. Selvin, L. A. Stevens et al., "Prevalence of chronic kidney disease in the United States," Journal of the American Medical Association, vol. 298, no. 17, pp. 2038-2047, 2007.

[53] H. Shamoon, H. Duffy, N. Fleischer et al., "The effect of intensive treatment of diabetes on the development and progression of long-term complications in insulin-dependent diabetes mellitus," The New England Journal of Medicine, vol. 329, no. 14, pp. 977-986, 1993.
[54] B. A. Perkins, L. H. Ficociello, K. H. Silva, D. M. Finkelstein, J. H. Warram, and A. S. Krolewski, "Regression of microalbuminuria in type 1 diabetes," The New England Journal of Medicine, vol. 348, no. 23, pp. 2285-2293, 2003.

[55] P. P. Wolkow, M. A. Niewczas, B. Perkins et al., "Association of urinary inflammatory markers and renal decline in microalbuminuric type 1 diabetics," Journal of the American Society of Nephrology, vol. 19, no. 4, pp. 789-797, 2008.

[56] T. Saito, M. Urushihara, Y. Kotani, S. Kagami, and H. Kobori, "Increased urinary angiotensinogen is precedent to increased urinary albumin in patients with type 1 diabetes," American Journal of the Medical Sciences, vol. 338, no. 6, pp. 478-480, 2009. 


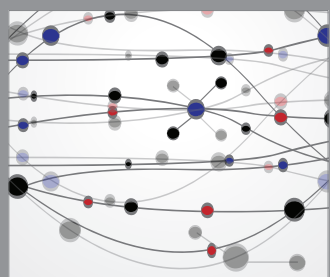

The Scientific World Journal
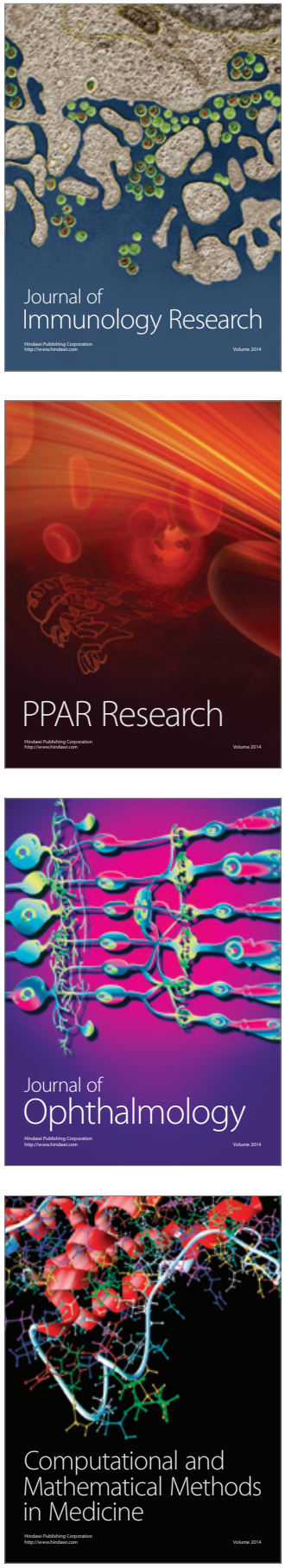

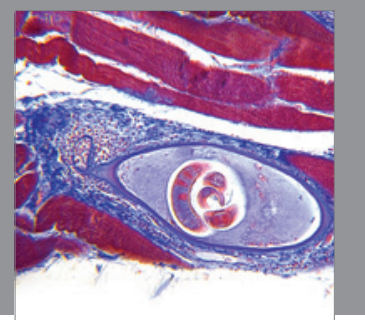

Gastroenterology

Research and Practice
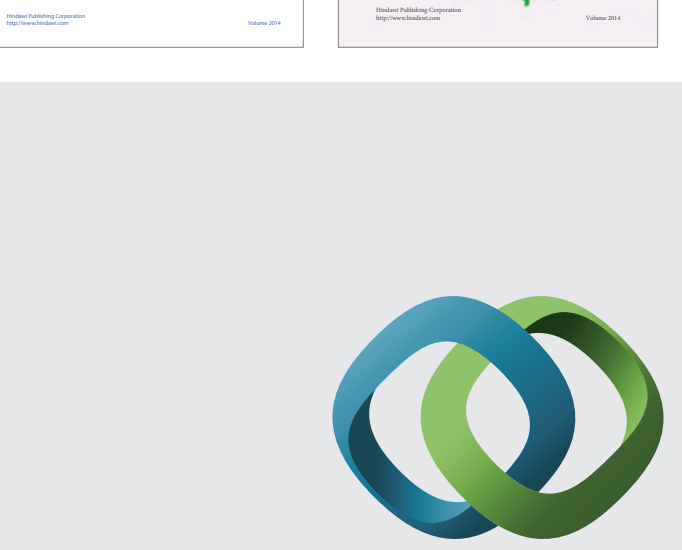

\section{Hindawi}

Submit your manuscripts at

http://www.hindawi.com
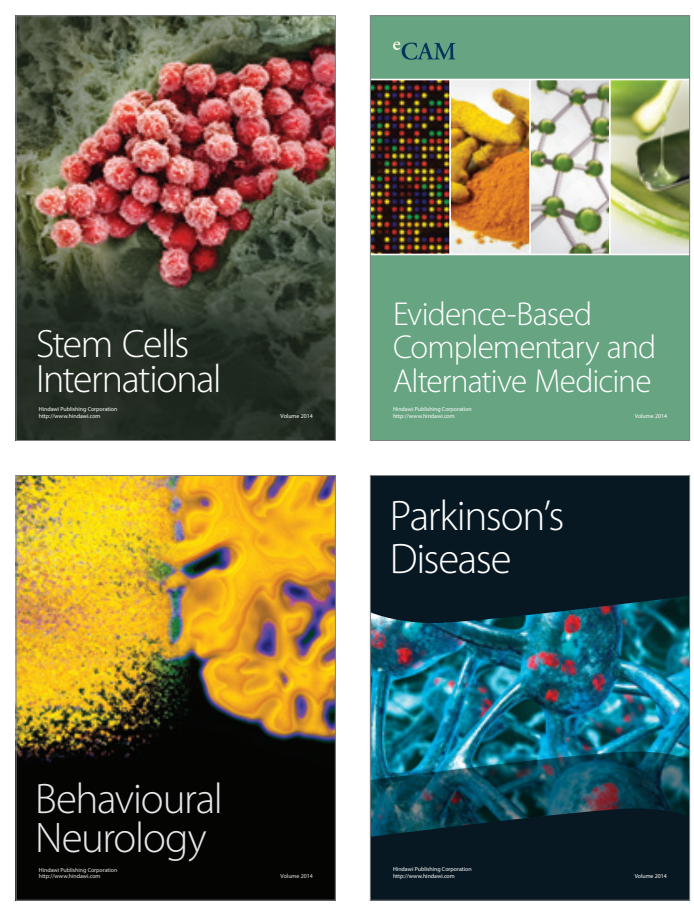

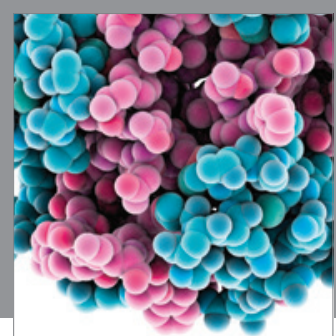

Journal of
Diabetes Research

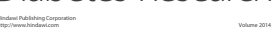

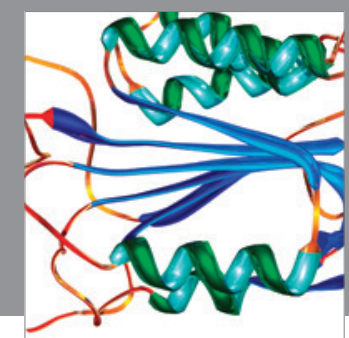

Disease Markers
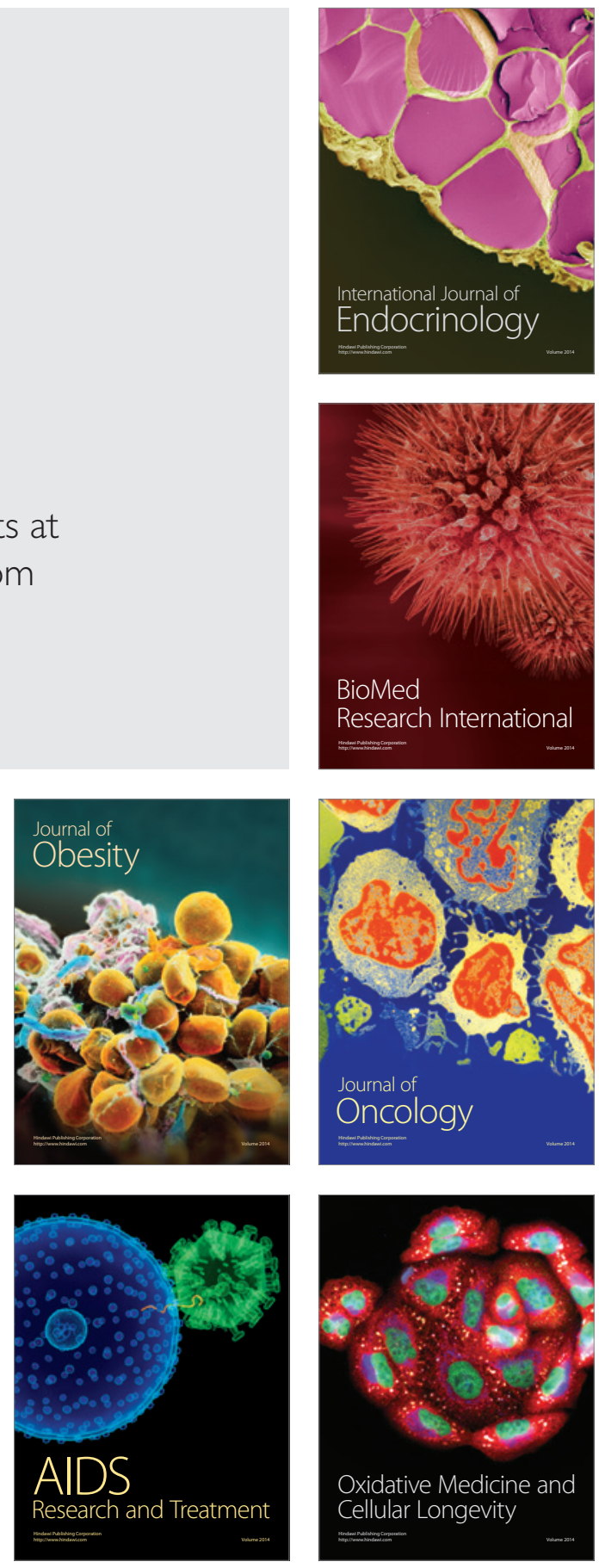